\title{
Medellín reescreve seus bairros ${ }^{1}$ - Urbanismo Social 2004-2011
}

\author{
Alejandro Echeverri \\ URBAM, Universidade EAFIT, Medellín, Colômbia \\ Contato: aecheverri@aevarquitectos.com
}

Durante os últimos quinze anos Medellín passou por um processo de transformação urbana e social que despertou o interesse em todo o mundo. Deixou de ser um lugar "invisível", depois de ser considerada uma das cidades mais violentas do planeta, para se transformar em um ponto de referência ou de encontro para os processos e inclusão de inovação. Mas a análise da experiência de Medellín, que poderia ser útil para outras cidades com condiçóes similares, deve ser feita com prudência, com a consciência de que é um processo que está apenas começando, em um contexto social ainda de grande desigualdade e em um território com imensas ameaças ambientais.

Medellín é a segunda cidade em importância comercial e industrial da Colômbia e tem três milhóes e quinhentos mil habitantes em sua área metropolitana. Está situada sobre um vale atravessado pelo rio Aburra, cercada por montanhas. Sua geografia é desenhada por uma grande quantidade de riachos que descem de $2.200 \mathrm{~m}$ acima do nível do mar, na parte alta das cordilheiras de ambos os lados do rio, até $1.400 \mathrm{~m}$ no fundo do vale. A partir de 1950, quando a cidade possuía 350.000 habitantes, ocorreu um processo de crescimento explosivo originado pela migração rural deslocada pela violência, ocupando informalmente as duas encostas do norte do Vale.

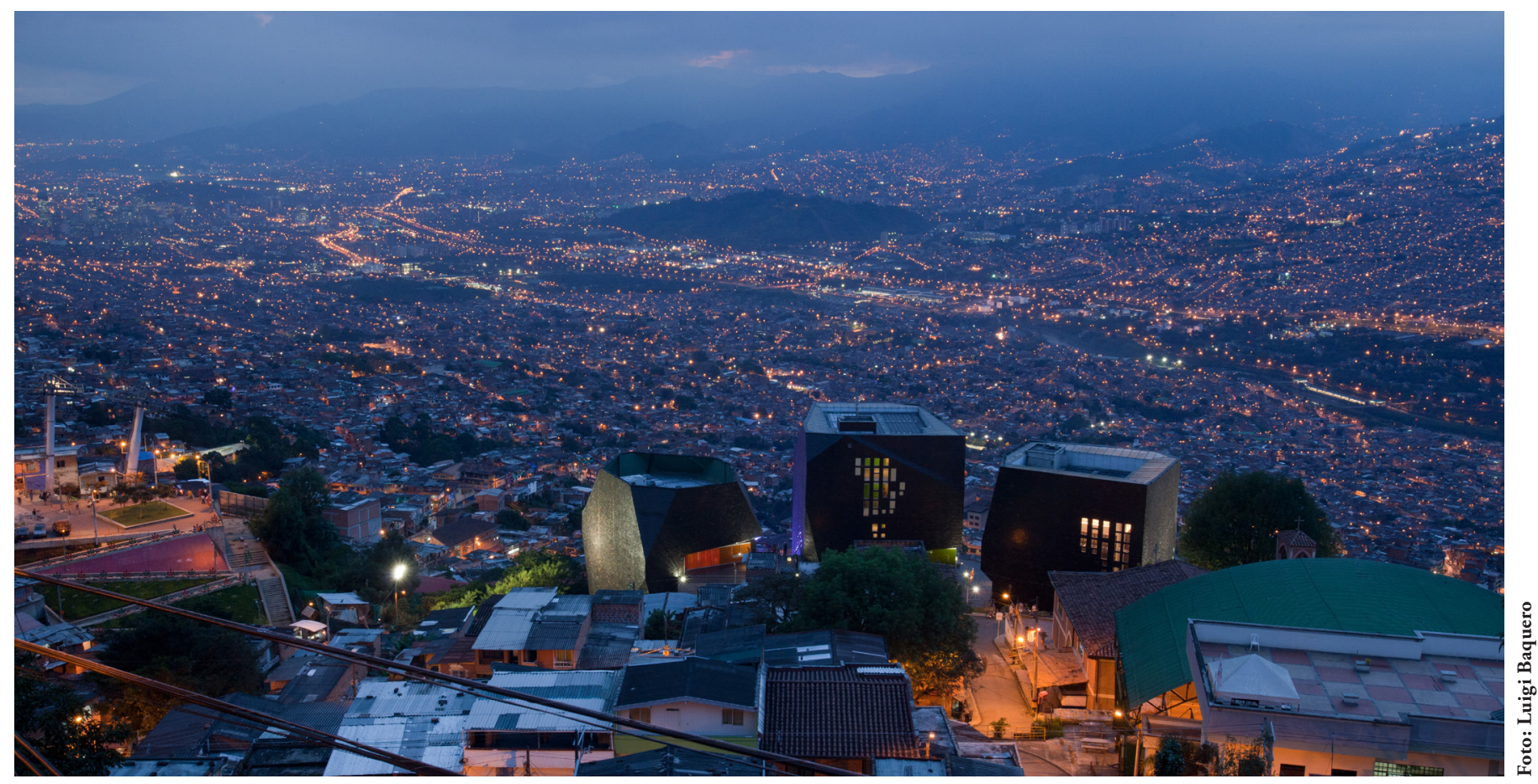

Medellin vista a partir de Santo Domingo Savio, Comuna 1, 2014.

1. Este artigo foi escrito a partir do texto elaborado para o livro "Shaping Cities: Emerging Models of Planning Practice" organizado por Mohammad Al-Asad e Rahul Mehrotra, editado por Hatje Cantz e Aka Khan Foundation, em 2016.

Revista online do Departamento de Arquitetura e Urbanismo da Pontifícia Universidade Católica -

Puc-Rio - Rio de Janeiro Brasil

Ano III - N III - ISSN 2446-7340 


\section{Reação à violência}

Durante as décadas de 1980 e 1990, o narcotráfico se apoderou de grande parte da cidade, tornando mais visível e evidente a segregação social. Os cartéis da droga dominavam as geraçóes de jovens que moravam nos bairros das encostas do Norte, popularmente chamados "Comunas"2. Em 1991 Medellín alcançou extremos inimagináveis, tendo sido a cidade mais violenta do mundo, com 381 mortos por 100.000 habitantes, quase 6.700 mortos, a maioria com menos de 26 anos. $\mathrm{O}$ retrato do drama desses anos originou alguns dos testemunhos mais duros e belos, como os filmes de Víctor Gaviria, "Rodrigo D: No Futuro" e "La Vendedora de Rosas", e o livro "No Nacimos Pa Semilla", de Alonso Salazar, entre outros. Estes documentos permitiram a muitos de nós enxergar a cidade real, entender seu espaço, sua geografia, seus ritos e tragédias. Também o programa semanal de televisão "Arriba mi Barrio", da Consejería para Medellín, dirigido por Alonso Salazar e Jorge Melguizo, que começou a ser transmitido em 1991, tornou visíveis, para toda a cidade, a vida e a cultura dos habitantes das "Comunas" do norte da cidade.

Durante os anos 1990, foram produzidos diferentes processos que buscavam açóes que respondessem ao drama que se vivia na cidade, liderados pela sociedade civil, setor privado, instituiçóes de ensino e organizaçóes não governamentais. Entretanto é o programa do Governo Nacional da Consejería Presidencial para Medellín (1990-1997) que compóe um espaço para o diálogo, o trabalho colaborativo e açóes reais de inclusão na cidade. Por intermédio da Consejería se engendraram açóes concretas que seriam a origem de alguns dos futuros modelos de transformação da cidade, como o PRIMED ${ }^{3}$, um programa de melhoramento integral de bairros desenvolvido entre os anos de 1992 e 1996 e que, com o apoio do governo alemão, foi o precedente fundador da estratégia de Urbanismo Social que viria posteriormente.

Ao final dos anos 1990, foram realizados dois projetos de espaço público de grande qualidade como instrumentos de mudança e inclusão social. $\mathrm{O}$ bom projeto e a arquitetura apareceram pela primeira vez depois de muitos anos. Sáo exemplos individuais isolados em lugares deteriorados do centro da cidade. Os dois casos mais representativos, deste momento, foram o Parque dos Pés Descalços (1999) e o Parque dos Desejos (2002), ambos promovidos por Empresas Públicas de Medellín (EPM) e pelo governo da cidade.

É importante notar que, entre 1995 e 2003, Bogotá esteve imersa em um excepcional processo de transformação urbana e cultural. Os prefeitos Antanas Mockus e Enrique Peñalosa lideraram, por três governos sucessivos, em um momento de violência, uma nova luz na política colombiana. Mockus deixou um legado de programas e açóes de gestão cultural e social que terminaram de forma inovadora e criativa. $\mathrm{O}$ governo de Peńalosa realizou uma transformação urbana sem precedentes, tendo como prioridades a mobilidade e o espaço público. Estes excelentes governos criaram um desafio para outras cidades do país. O exemplo e o valor desta experiência foram fundamentais para o processo posterior que teria Medellín.

Simultaneamente, em 2002, teve início o mandato presidencial de Alvaro Uribe Vélez, com uma política nacional de enfrentamento contra a guerrilha e a delinquência, chamada Segurança Democrática. A presença do exército e da polícia foi intensificada tanto em áreas rurais como urbanas. $\mathrm{O}$ momento mais doloroso da aplicação desta política em Medellín, aconteceu na Comuna 13, com a Operação Orión, através de uma guerra urbana que afetou grande parte da populaçáo civil. Em 2003, enquadrado na Lei de Justiça e Paz, o governo nacional assinou um tratado para a desmobilização das autodefesas rural e urbana - um grupo armado

2.Termo utilizado na Colômbia para se referir a uma unidade administrativa na qual é subdividida uma área urbana de uma cidade.

3.Programa Integral de Mejoramentos de Barrios Subnormales de Medellín. 


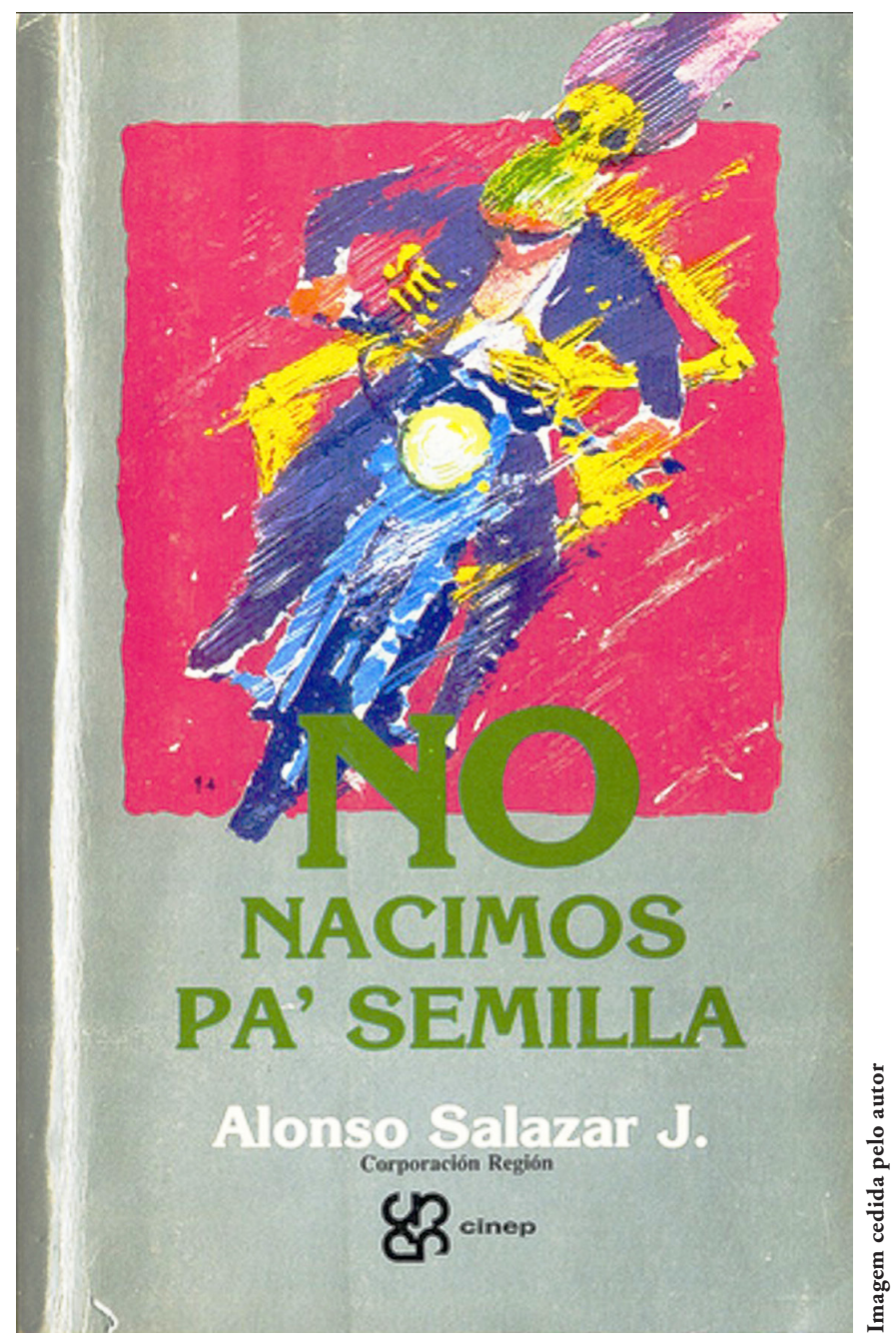

Capa do livro No Nacimos pa Semilla, de Alonso Salazar, 1990.

paramilitar. A desmobilização e entrega de armas começa em Medellín, dando início a um complexo processo de reintegração à sociedade.

\section{As instituiçóes de ensino}

Nos anos 1990, a Universidade Nacional e a Universidade Pontifícia Bolivariana (UPB) decidiram direcionar uma parte importante de seus projetos e programas de pesquisa para os bairros das encostas do Norte, as "Comunas". Este território da cidade, até aquele momento pouco estudado, onde ocorriam muitos dos problemas sociais e de violência com questôes de desigualdade e exclusão, se transformou em um laboratório de inovação e aprendizado principalmente para as escolas de arquitetura e urbanismo. Em 2001, com um grupo de professores e estudantes da Faculdade de Arquitetura da UPB, fundamos a "Oficina de Projetos do Norte", no qual, com um grupo de pesquisa interdisciplinar, buscávamos soluçốes de média e pequena escalas para alguns dos bairros emergentes e com problemas estruturais de violência nesses setores da cidade.

Em 2003, o então candidato do movimento cívico Compromisso Cidadáo à prefeitura, o matemático Sergio Fajardo, nos convidou a auxiliá-lo na elaboração de seu plano de governo no componente urbano. Ao ganhar as eleiçôes, nomeou-me diretor da Empresa de Desenvolvimento Urbano (EDU). Ali formamos um escritório de projetos urbanos integrado por funcionários da instituição, especialistas externos e parte da equipe da Oficina do Norte. A EDU é uma instituição pública da prefeitura de Medellín que havia sido criada anos antes para gerenciar projetos de renovação urbana para o centro da cidade.

Em parceria com a equipe de governo da prefeitura, redefinimos a EDU para transformá-la em um escritório de projetos urbanos e em uma agência de execução de obras estratégicas de infraestrutura. A articulação e coordenação entre os diferentes departamentos dentro do governo foram possíveis a partir de uma equipe com dedicação exclusiva para a gestáo destes projetos estratégicos, que dependiam diretamente do prefeito. Na EDU lideramos a estratégia de Urbanismo Social, além da implementação e do desenvolvimento dos Projetos Urbanos Integrais (PUI), dos programas dos Parques Bibliotecas, do Projeto da Zona Norte, entre muitos outros.

\section{A política}

As forças sociais, que tinham começado a se formar enquanto a cidade suportava a violência dos anos 1980 e 1990, teriam a oportunidade de executar 
as propostas formuladas na busca por uma cidade mais inclusiva. O ano de1999 foi o da fundação do Compromisso Cidadão, o movimento cívico liderado pelo acadêmico Sergio Fajardo e pelo escritor Alonso Salazar, acompanhados por pessoas de instituiçốes de ensino, da empresa privada e de organizaçóes sociais. Fajardo participou das eleições para prefeito da cidade de Medellín nesse ano, ficando em segundo lugar, disputando com os partidos e grupos de poder tradicionais. Continuou liderando o movimento cívico e ganhou as eleiçóes de 2003 com o número de votos mais elevado na história das eleiçôes municipais, assumindo o cargo em janeiro de 2004.

Esta reforma política foi vital para que ocorresse a transformação urbana e social, para começar a escrever a nova história de Medellín e muitos dos processos que hoje continuam. Fajardo, como prefeito da cidade, lidera um processo ao qual, entre os anos 2004 e 2007, se juntaram líderes e especialistas de diferentes ideologias. Compartilhavam a urgência de efetuar uma mudança estrutural, resgatando a ética como razão central na política e tendo como objetivo recuperar a confiança no poder público por meio de programas de inclusão, educação e projetos urbanos, próximos à realidade das pessoas. $\mathrm{O}$ escritor Alonso Salazar se elegeu prefeito da cidade para o período 2008-2011, dando continuidade aos programas de governo.

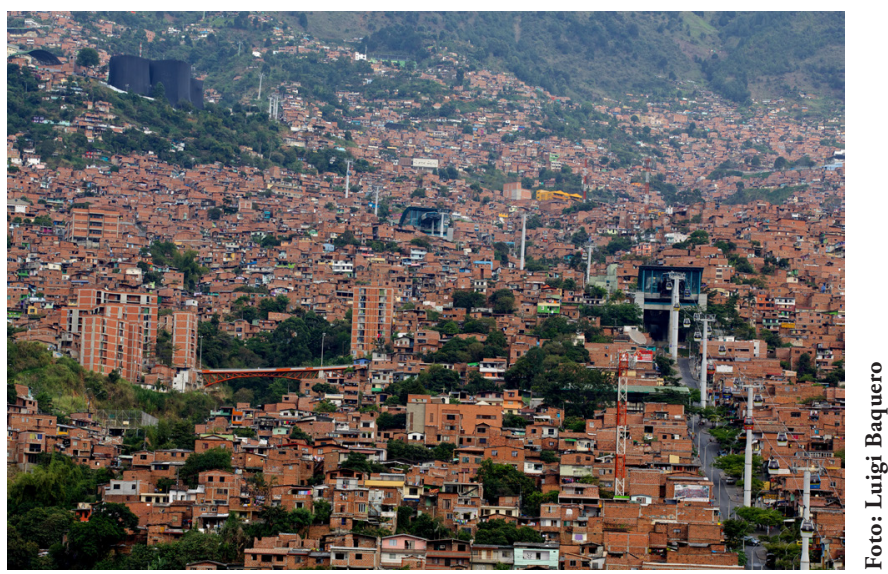

Projeto Urbano Integral Nordeste, Comunas 1 e 2. 2014.

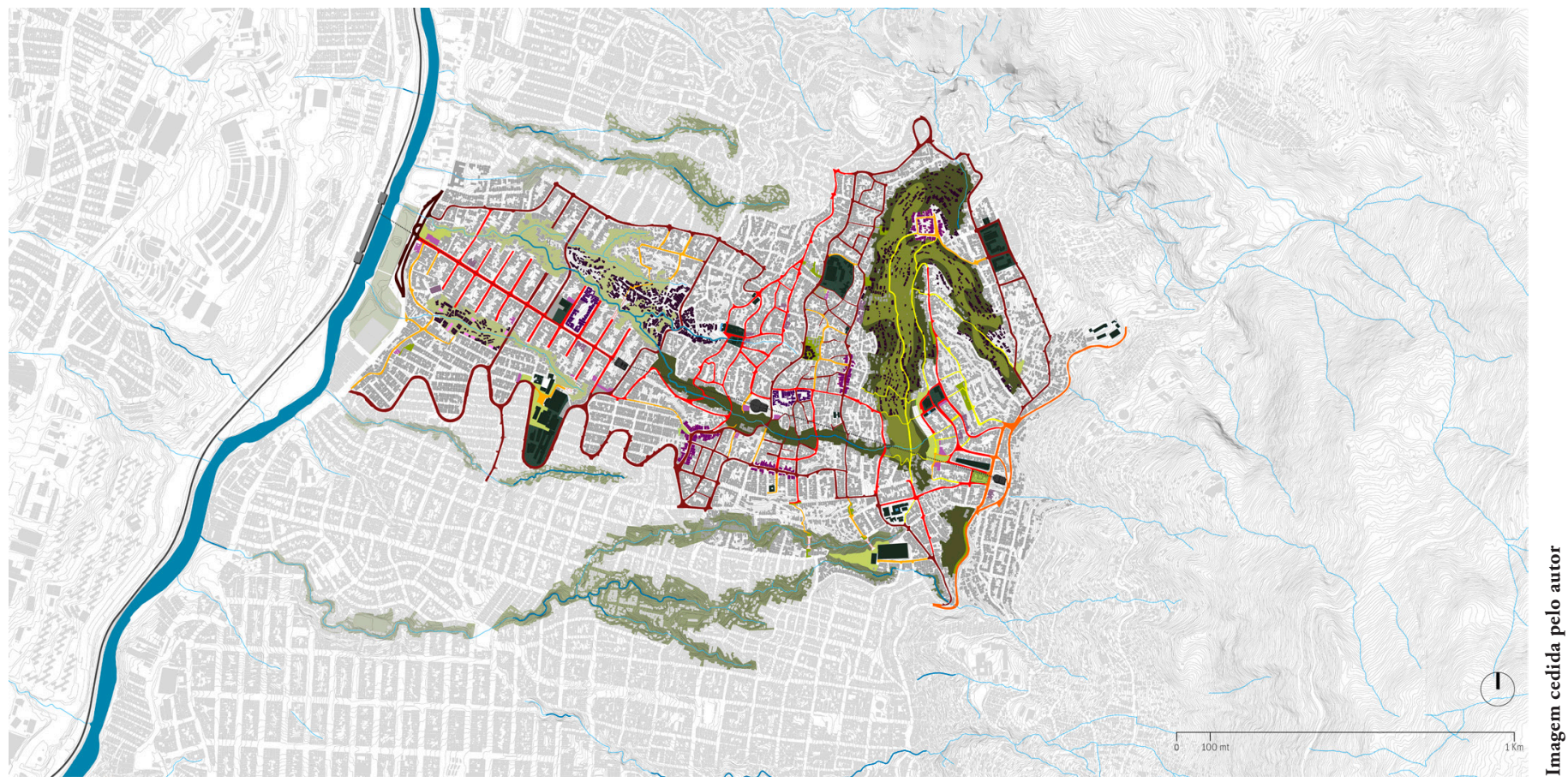

Plano do PUI, Empresa de Desenvolvimento Urbano (EDU).

Revista online do Departamento de Arquitetura e Urbanismo da Pontifícia Universidade Católica - 
Um dos atributos essenciais de Fajardo, Salazar e outros protagonistas importantes destes dois períodos de governos cívicos foi a capacidade de construir pontes e espaços de colaboração. $\mathrm{O}$ relato que se começou a escrever partiu de uma realidade simples, mas essencial: a sensibilidade e capacidade para se aproximar e se comunicar com a cidade dando respostas aos habitantes dos setores excluídos. Medellín se transformou em um laboratório vivo, em um espaço de inovação, por meio de programas sociais de educação e cultura, focados nos bairros do norte da cidade, onde estavam os problemas de desigualdade mais estruturais.

Porém são a arquitetura e o urbanismo as ferramentas estratégicas para tornar visíveis os programas de governo nos bairros da cidade. A crise e a violência fizeram que muitas das ruas da cidade fossem territórios de grupos à margem da lei, onde se dava a expressão do temor. A grande aposta foi tornar a cidade transparente, abri-la, produzir confiança e fazer uma troca de percepção para construir um mapa total da cidade. A transformaçáo do espaço público foi uma das ferramentas estratégicas para a recuperação da confiança da populaçáo em Medellín. Fajardo costumava dizer em relação a esta transformação urbana: "estamos trocando a pele dos bairros de Medellín". A esta estratégia de "troca de pele" que combina de forma simultânea programas sociais, culturais e de educação com projetos de arquitetura e urbanismo, damos o nome de Urbanismo Social.

\section{Urbanismo Social 2004-2011}

A transformação física que Medellín reconheceu é a expressão tangível de uma mudança que, ainda que frágil, teve um impacto fenomenal nos habitantes da cidade. Esta transformação parte de uma posição ética que dirige os processos para dar respostas a contextos sociais excluídos da cidade. Os desenhistas, arquitetos e urbanistas se viram confrontados com realidades de alta complexidade, o que lhes exigiu uma sensibilidade especial para valorizar e entender as dinâmicas locais.

A necessidade de construir espaços de mediação entre os programas e projetos do governo - top down - e as dinâmicas e comunidades locais - bottom up -, exigiram maior inovação e criatividade. A transformação do espaço urbano se converteu em uma ferramenta efetiva e visível para coordenar os diferentes programas e projetos nos bairros selecionados. Os projetos de arquitetura e urbanismo a partir da grande quantidade de açôes de diferentes escalas tornaram tangíveis, no território, os diferentes programas do governo e ajudaram a organizar os espaços de articulação entre as instituiçóes, os diferentes atores e as comunidades.

A estratégia de Urbanismo Social liderou a confluência desses processos em zonas estratégicas, buscando articular harmonicamente os diferentes programas com os projetos de transformação física. Nós nos apoiamos muito no sentido comum, definindo como tática principal, restaurar a dignidade dos itinerários urbanos mais intensamente utilizados pelas pessoas dos bairros e

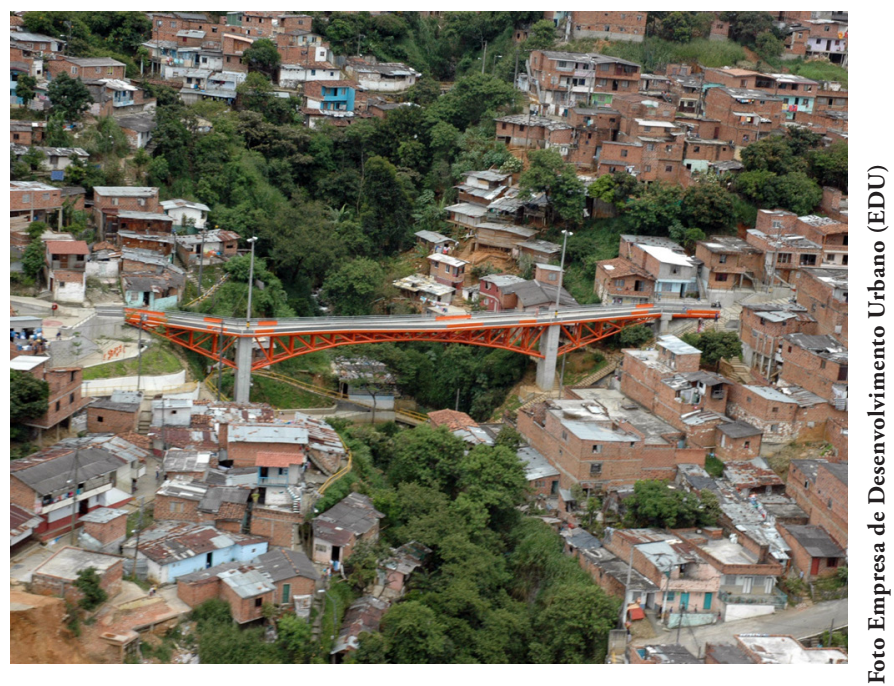

Ponte Bairros Andaluzia e França, Comunas 1 e 2. 
usá-los como uma sequência encadeada de açóes e programas.

Esta experiência de transformação urbana e social de Medellín foi também um meio para criar ferramentas práticas e desenvolver novas capacidades institucionais. Desses oito anos de governos cívicos ficam muitos aprendizados e algumas ideias.

\section{Sete ideias}

Entre os anos de 2004 e 2011, por meio da estratégia de Urbanismo Social, foram realizadas importantes inovaçóes. Este programa se concretizou como uma ferramenta de intervenção urbana que denominamos de Projetos Urbanos Integrais (PUI). Um instrumento operacional que, mediante projetos urbanos de escala intermediária, retrata um processo holístico para desenvolver a concepção, o projeto e a execução de obras de infraestrutura, articulados com diferentes programas governamentais.

Os PUIs foram liderados na EDU e concebidos para romper a dinâmica trágica que historicamente apresenta o Plano de Ordenamento Territorial (POT) de Medellín, um plano sem possibilidades de aplicação prática em contextos urbanos extremos. O desafio era passar do plano para a ação, para um processo de transformaçãa integral centrado em ações concretas sobre o território que pudesse ser escalado em etapas.

Posteriormente, em 2010, com o objetivo de consolidar e sistematizar os processos urbanos da cidade e abordar novos desafios e perguntas, cofundamos o URBAM, um centro de estudos urbanos e ambientais na Universidade EAFIT.

Nossos principais focos de trabalho são os territórios emergentes com problemas de desigualdade e exclusão. Entendemos a experiência de Medellín como um laboratório de aprendizado contínuo e, depois de vários anos desde que se implementou a estratégia de Urbanismo Social em
Medellín, cremos que são sete as ideias nas quais se fundou o programa. Estas ideias podem servir como referência metodológica para outros processos com características semelhantes, mas principalmente abrem espaço para dirigir a experiência de Medellín para novas perguntas e desafios. Estas sete ideias são as seguintes:

\section{Zonas em Ação - Enquadramento}

Era prioritário ser estratégico e seletivo para definir com clareza quais seriam as Zonas em Ação no processo de implementaçáo dos PUIs. A capacidade dos governos é limitada em recursos econômicos e humanos para a alta dificuldade dos problemas a se resolver. $\mathrm{O}$ tamanho e a definição dos limites das áreas funcionaram como estratégias de enquadramento que foram singulares em cada um dos casos. Estes processos são de alta complexidade e requerem uma grande convicção e determinação política para manter o foco de atenção nestas zonas estratégicas.

Era determinante ter sucesso nos primeiros exemplos de intervenção e selecionar lugares reconhecidos, na memória urbana, como problemas históricos da cidade. Em Medellín, os primeiros a serem identificados foram o setor Nordeste e a Zona Norte em Moravia, que representavam zonas vulneráveis afetadas por altos índices de violência, mas também tinham a possibilidade real de se integrar à cidade. Foi necessário desenvolver uma articulação institucional eficiente para fazer confluir nessas zonas uma grande diversidade de programas e projetos coordenados harmonicamente.

\section{Projetos Holísticos - Confluência}

Os Projetos Urbanos Integrais (PUI) implementados nas Zonas em Ação se transformaram na ferramenta mais eficiente para poder conceber, desenhar e coordenar um processo 


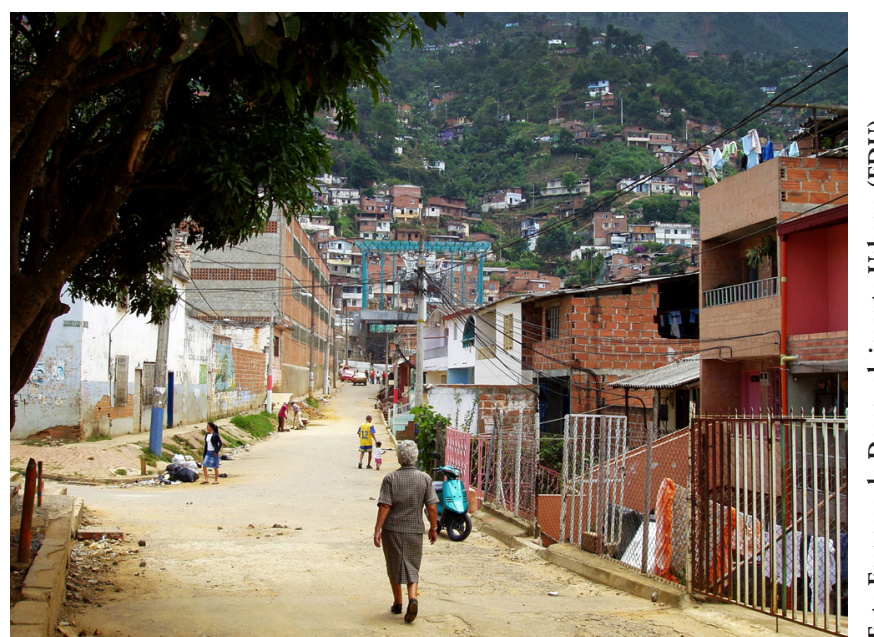

Passeio da rua 106 em Santo Domingo Savio, Comuna 1, antes da intervenção, 2003.

holístico de grande complexidade, tentando articular harmonicamente os diferentes programas de governo no âmbito dos diferentes processos de transformação física. Os PUIs tentavam fazer com que as políticas públicas se confluíssem nestas zonas, combinando a implementação dos programas estratégicos do governo, como educação e cultura, com um processo de construção de obras de arquitetura e urbanismo em diferentes escalas.

Esta estratégia implementou projetos de grande impacto e magnitude, como o Metrocable (Teleférico) e os projetos de habitação, ou o programa dos Parques Biblioteca, combinados de forma simultânea com intervençóes de menor tamanho e escala local, como a reurbanização das ruas e passeios. A união dos projetos de transformaçáo física de diferentes escalas e usos com uma grande diversidade de programas governamentais se ordenou em um processo definido em fases precisas e açóes visíveis e verificáveis. Foi concebido um processo desenvolvido a partir de projetos relacionados com a vida cotidiana das pessoas. A combinação simultânea de políticas governamentais com açóes de iniciativa local multiplicou as oportunidades reais dos processos de colaboraçáo.

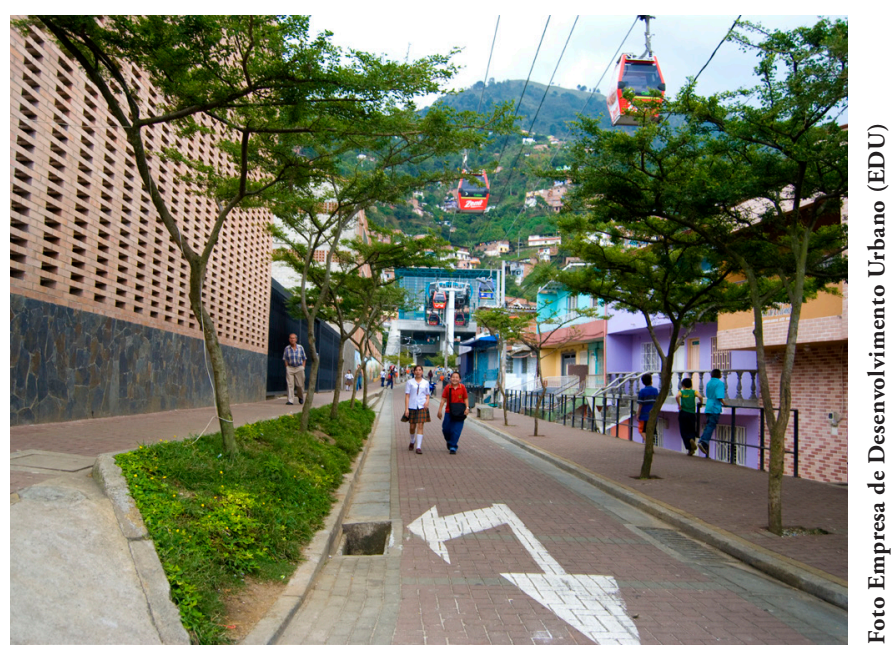

Passeio da rua 106 em Santo Domingo Savio, Comuna 1, depois da intervençâo, 2008.

\section{Projetos de conexâo - União}

Uma característica das zonas de intervenção selecionadas é que são lugares segregados e com graves problemas de integração com a cidade. A prioridade foi mudar sua condição de isolamento em relação ao processo de desenvolvimento social e econômico da cidade e converte-las em parte integrante da mesma. Tentava-se desfazer as fronteiras visíveis e invisíveis que o causavam, unindo as comunidades e seus bairros à cidade formal.

Modificar o preconceito sobre estas zonas e vêlas como parte integrante da cidade, mas com condiçóes temporárias de isolamento, permitiu um olhar mais completo e transparente sobre o território em geral. Isso possibilitou a identificação de oportunidades estratégicas para localizar novos projetos e programas de conexão e uniáo.

Dois tipos de ações de conexão foram estabelecidos em Medellín: os projetos para criar novas conexóes e os programas para localizar novas atividades de integraçáo. $\mathrm{O}$ primeiro tipo respondeu a intervençóes como os novos sistemas de transporte público por cabo combinados com projetos de escala local, como as novas pontes, passeios e 
calçadas, buscando uma ação capilar de conexão. $\mathrm{O}$ segundo tipo buscou a inserção de novos programas de atividades e serviços, com equipamentos de grande impacto localizados estrategicamente. Deste fizeram parte projetos como o Museu de Ciência e Tecnologia Explora, o Centro Cultural de Moravia ou o Parque Biblioteca La Quintana.

\section{Cidade Transparente - visibilidade}

O reconhecimento da cidade real, que procura estender as dinâmicas urbanas, culturais e econômicas a algumas das áreas segregadas de Medellín, foi um dos aspectos mais valiosos da estratégia de Urbanismo Social. Foi uma decisão política corajosa ter definido como prioritárias estas zonas na agenda do governo e tê-las feito visíveis por meio de debates públicos e projetos estratégicos. $\mathrm{O}$ processo de mudança da cidade se inicia quando o mapa mental de grande parte de seus habitantes começa a incluir toda a cidade, e não apenas um fragmento dela.

O governo municipal aumentou a rede de mobilidade com novos corredores de transporte público de média e alta capacidades, que, como o Metrocable (Teleférico) ou o Metroplús (uma espécie de BRT), conectaram estes bairros isolados ao sistema integrado do metrô de Medellín. A experiência de atravessar a cidade e torná-la visível foi uma ferramenta física e psicológica muito potente para iniciar o processo de inclusáo das comunidades marginalizadas. Este primeiro passo

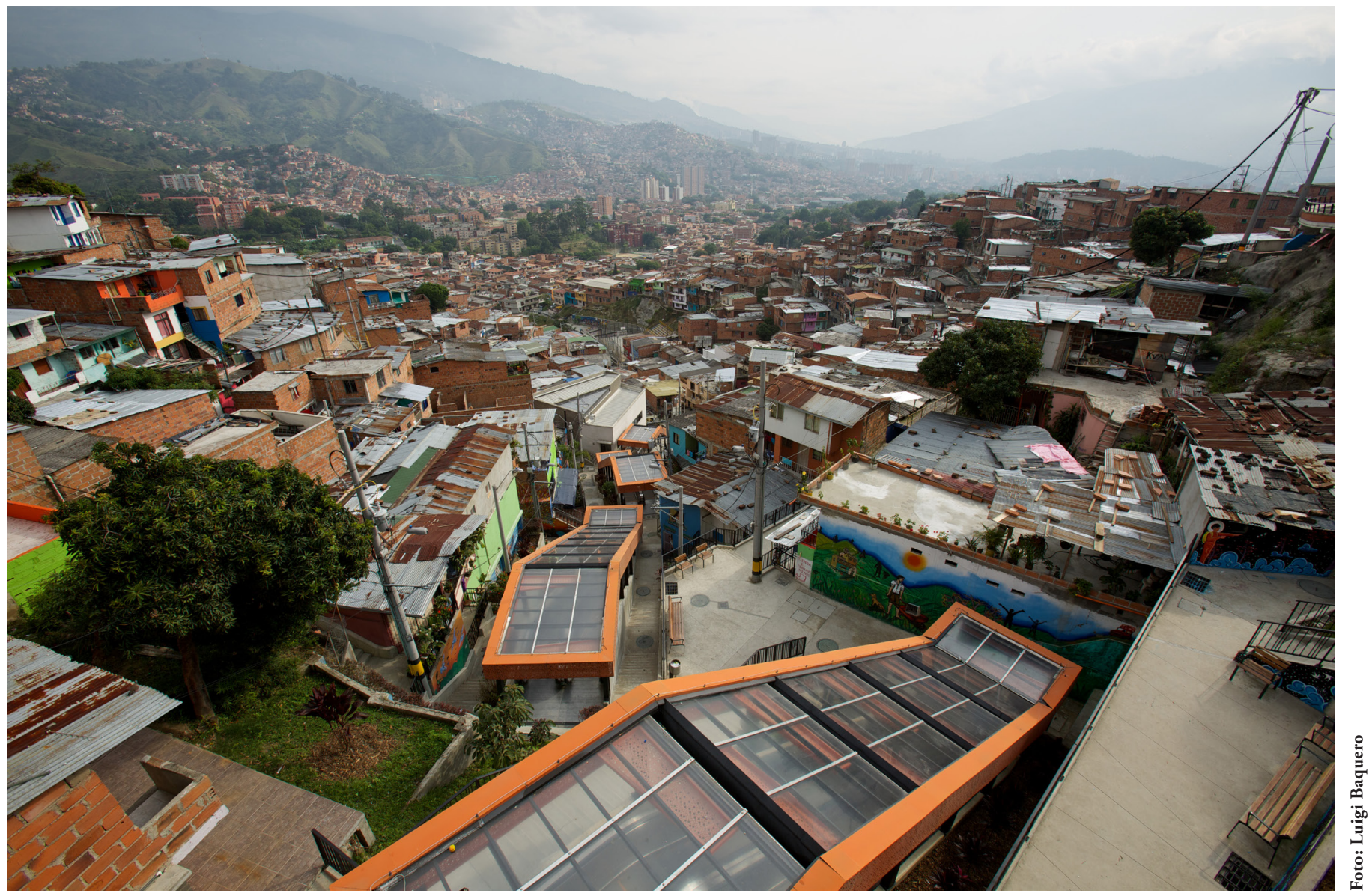

Escadas rolantes da Comuna 13, 2014.

Revista online do Departamento de Arquitetura e Urbanismo da Pontifícia Universidade Católica -

Puc-Rio - Rio de Janeiro Brasil

Ano III - N III - ISSN 2446-7340 
de tornar visível a cidade real foi essencial na busca da transformação urbana e social de Medellín.

Novos projetos de arquitetura emblemáticos foram construídos nas áreas de intervenção estratégica com programas integrais de educação, cultura e serviços para serem usados por todos os habitantes da cidade. A presença destes novos pontos de referência foi importante para tornar mais transparente e intenso o intercâmbio das pessoas que vivem nesses bairros com o resto dos habitantes da cidade. Contudo, é a ressignificação da identidade destas comunidades o aspecto que possibilita uma integração real com a cidade. E para isso foram essenciais a recuperação e a transformação de uma quantidade significativa de rua, passeios, calçadas, praças e parques.

\section{Dignidade Social-Qualidade}

A mudança de paradigma relacionada com o esforço de melhorar a qualidade do projeto e da elaboração das obras de infraestrutura teve um papel chave na criação de uma alteraçáo positiva de percepção da cidade, em relação às comunidades e das comunidades em relação ao resto da cidade. Foi estratégico aumentar o padrão de exigência na concepção dos projetos. A obra pública passou a ser um atributo que tentou dar um novo sentido de identidade e significado aos habitantes desses bairros marginais.

O sentimento de dignidade tem um papel importantíssimo nos processos de inclusão social. A autoestima e o orgulho estâo relacionados diretamente com o subconsciente das crianças, dos jovens e dos adultos e com o sentimento de admiração e apreço pelos lugares que se frequentam cotidianamente. O governo da cidade buscou elevar a qualidade, melhorando o nível das equipes internas de projeto e promovendo uma cultura de convocatórias e concursos públicos de arquitetura e urbanismo para suas obras mais representativas.

A qualidade dos projetos de arquitetura e urbanismo, combinada com a integralidade e a pertinência dos programas de educação, cultura e empreendimento, está relacionada diretamente com a apropriação das comunidades sobre esses projetos e com a corresponsabilidade para a sua administração e manutenção. Elevar o padrão de qualidade tanto nos grandes projetos quanto nas pequenas obras garante que a população as adotem como próprias, reduzindo o risco de vandalismo.

\section{A "pele" do bairro - Proximidade}

A recuperação da "pele" dos espaços públicos produziu, em alguns dos bairros que sofreram intervençóes em Medellín, um forte e profundo impacto, devido à devolução para a população da oportunidade de usar a rua e se encontrar nos espaços públicos de uso cotidiano sem medo, trazendo de volta a confiança no outro. Geralmente estas ações de pequena escala, têm um impacto positivo mais estrutural do que os grandes projetos de infraestrutura, pela sua proximidade com o usuário. Um fator de indicação de civilidade está relacionado à qualidade e quantidade de lugares onde crianças, jovens e adultos possam desfrutar e habitar com segurança os espaços públicos.

Os melhores exemplos de recuperação cívica a partir de projetos integrais como o Passeio Andaluzia, a rua 106 e o Parque Mirador de Santo Domingo foram concebidos mediante o conhecimento detalhado do tecido urbano e dos processos locais. $\mathrm{O}$ tom dessas intervençôes é mais próximo de um sistema cuidadoso de adição de novas peças e usos a um tecido existente, do que de um projeto de renovação urbana buscando uma mudança total. Procurou-se inserir novos meios de colaboração e ações urbanas para ajudar a tecer e conectar as realidades existentes, assim como para estimular novas dinâmicas de melhoramento e desenvolvimento.

A rua vizinha, a esquina para o encontro, o parque do bairro e onde quer que as pessoas passem parte de sua vida diária, devem se transformar em 


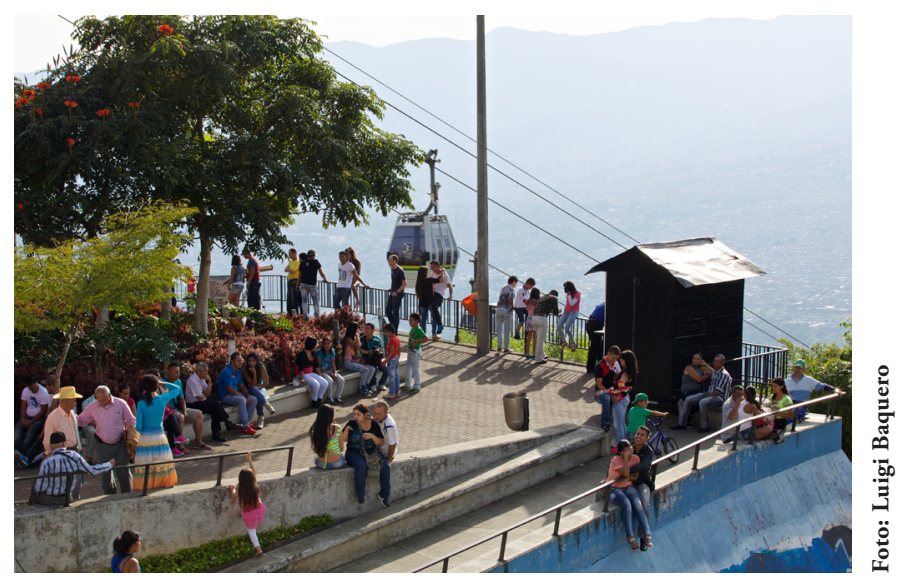

Parque Mirador em Santo Domingo, Comuna 1, 2014.

peças estratégicas de uma intervenção integral. $\mathrm{O}$ ensinamento mais poderoso que nos deixou a experiência da estratégia de Urbanismo Social em Medellín é a valorização do local. É este conceito de proximidade que demanda o maior desafio: de como usar a memória e os sonhos individuais e coletivos, a habilidade de recordar e, ao mesmo tempo, imaginar o cotidiano.

\section{Projeto dos processos - Cocriação}

Os novos projetos de arquitetura e urbanismo fizeram parte de uma ideia que seleciona zonas críticas da cidade para estabelecer novos meios de diálogo e colaboração. A ampla gama de atores, instituiçóes e etapas em seu desenvolvimento tornou obsoleto o desejo de um sistema perfeito e fechado e, por outro lado, esta realidade exigiu uma grande inteligência prática e senso comum. Foram processos imersos em uma realidade dinâmica e por isso foi essencial desenhá-los com grande flexibilidade e agilidade para serem ajustados.

É fundamental nestas zonas de conflito construir espaços de mediação em parceria com grupos culturais locais e líderes comunitários. Necessitou-se destas sociedades para construir uma plataforma de confiança e para ampliar a base de novas lideranças. É por isso que nos melhores exemplos, como foram o Projeto Urbano Integral Nordeste ou o da Zona Norte, o projeto do processo de colaboraçáo para desenvolvê-los foi tão importante quanto as próprias obras de transformação física.

Para cada "Zona em Ação” se definiu um líder, um cabeça do grupo que organizou e representou a equipe de governo com as comunidades locais. Sua maior responsabilidade foi firmar acordos e compromissos com os grupos locais e fazêlos cumprir por meio de uma coordenação interinstitucional eficiente. A construção de confiança desse dá nas relaçôes pessoais e no cumprimento dos acordos; esta é a chave que garante qualquer processo de colaboraçáo.

\section{Liçóes}

A base do sucesso dos meios de colaboraçáo entre as comunidades e o governo, entre as equipes técnicas e os líderes locais está na habilidade para se construir espaços fundamentados no respeito e em

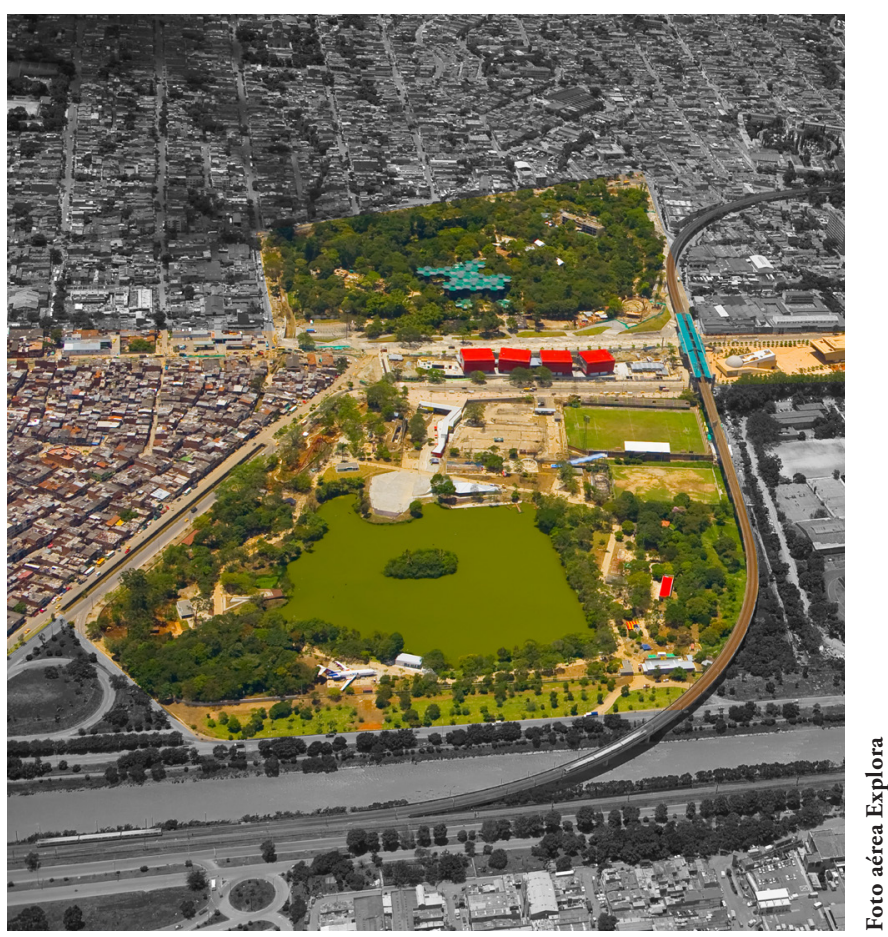

Parque de Ciência e Tecnologia Explora, Zona Norte, 2007. 


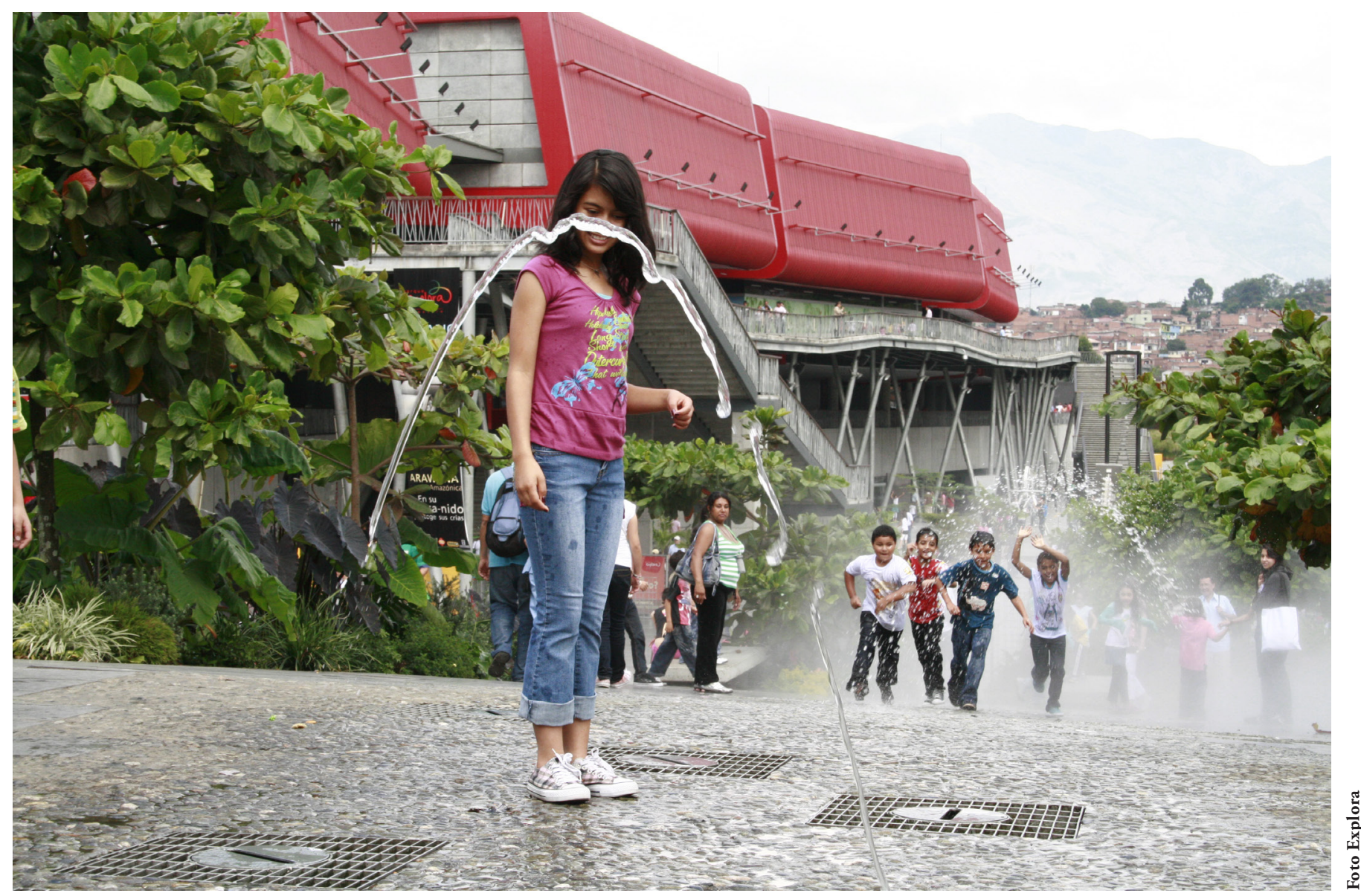

Foto a partir da praça, 2010.

uma linguagem comum. Em uma realidade repleta de preconceitos de ambos os lados é imprescindível que todos compreendam da mesma forma $o$ significado das palavras, sendo esse o primeiro passo para se realizar um processo transparente. Afinal, comunicação e confiança compóem a base de qualquer processo de colaboração.

A capacidade de reconhecer os valores e atributos das realidades sociais e físicas dos bairros deve ser o ponto de partida, principalmente quando se está trabalhando em setores com altos níveis de precariedade. Apreender mais de suas preexistências, sonhos, códigos, formas de construção e representação local, uma informação valiosíssima para que se possa adaptar de diferentes maneiras. A cidade não é uma folha em branco.
A noção do projeto urbano como um processo finito, em que a transformação das infraestruturas se concebem como momentos congelados, desenvolvidos com um plano de trabalho predefinido e rígido, e no qual o físico está separado das dinâmicas sociais, é um equívoco. A realidade da cidade, especialmente a dos bairros informais, é um processo vivo de múltiplas camadas. Pertence mais à noção de um processo progressivo e simultâneo, no qual deve ser permitido retirar ou adicionar peças. Esta posição redefine muitos princípios da concepçáo clássica do projeto urbano que busca uma segurança disciplinar mais simples.

O princípio da transformação da cidade deve se apoiar mais na ideia da adição e na noção de um processo de múltiplas açóes de pequena escala 
conectadas, ao contrário da forma convencional de pensamento a partir de grandes infraestruturas ou grandes projetos urbanos como soluçôes dominantes. Pode-se transformar uma cidade ou criar um novo sistema urbano por meio de uma estratégia viral de repetição de projetos e açôes de pequena e média escalas. Este princípio nos permite construir espaços de mediação e colaboração com as comunidades e desenhar um processo mais flexível e inclusivo de cocriação com vários atores.

A sustentabilidade dos programas será garantida ao se elaborar um processo que inclua, desde sua fundação, múltiplos parceiros corresponsáveis por eles. Dependerá da capacidade de implicar atores e instituiçóes diversas desde o momento de sua concepção até a sua ativação e administração, gerando projetos e programas escaláveis com capacidade de crescer ao longo do tempo e, fazendo parte, assim, de um processo de constante reinvenção.

A priorização de áreas com problemas sociais e de exclusão para serem integradas às dinâmicas da cidade foi o método no qual se apoiou a estratégia de Urbanismo Social. Os melhores exemplos, em Medellín, uniram harmonicamente transformaçōes em infraestruturas físicas, programas e atividades a processos de colaboração local. Esta recente experiência em Medellín deixa algumas liçóes, sendo a principal delas o fato de que pode se transformar uma realidade, ou melhor, iniciar o caminho de uma transformação quando se consegue construir um relato comum, uma narrativa que responda a desejos e a objetivos coletivos e que, quando seus líderes se unem em torno de uma ideia próxima à realidade da populaçáo desenvolvemna com convicçáo e criatividade. Mas o ponto de ruptura, no caso de Medellín, foi uma posição ética e moral como resposta a um problema de exclusáo e violência.

É claro que esses processos de transformação e inclusão ainda são muito frágeis e incompletos e se encontram ameaçados por duas razóes. A primeira é a falta de continuidade pela incerteza característica da política. A segunda é a falta de uma distância que nos permita ver com maior clareza o que se conseguiu e quais são as lacunas desse processo no complexo contexto da realidade de Medellín.

Mas estes serão temas para outra reflexão. 